\title{
Shunt Nephritis: Efficacy of an Antibiotic Trial for Clinical Diagnosis
}

\author{
Eisei Noiri, Shoji Kuwata, Kazuo Nosaka, Akihide Nakao, Shigeo Taniguchi, Joji Seki, \\ Shu Uwatoko, Keiji Suzuki, Masafumi Fukagawa, Toshihiro OKuda and Kiyoshi Kurokawa
}

\begin{abstract}
Coagulase negative staphylococcus, a normal skin flora, is especially nosopoietic under shunt management, because coagulase negative staphylococcus sometimes forms a biofilm around itself at catheter tips in vivo, which shields the organism from the effects of antibiotics. But it is difficult to distinguish this pathogen from a possible confounding contamination of a blood culture. In this article, we report a case, and discuss how a patient with suspected shunt nephritis should be examined and treated. In addition, to further histological and prognostic interpretation, we review the previously reported cases of shunt nephritis in Japanese adults. (Internal Medicine 32: 291-294, 1993)
\end{abstract}

Key words: coagulase negative staphylococcus, Japanese adult cases, membranoproliferative glomerulonephritis (MPGN), ampicillin (ABPC)

\section{Introduction}

So called 'shunt nephritis' was originally reported by Black et al in 1965 (1), in two pediatric cases of nephrotic syndrome with macroscopic hematuria, associated with long-standing coagulase negative staphylococus bacteremia following ventriculoatrial shunt operation for the relief of hydrocephalus. Because it is characteristic of this disease that there is a relatively long interval from the time of shunt placement to the recognition of symptoms, it is sometimes difficult to distinguish this disease from primary glomerulonephritis in actual clinical practice.

In this paper, we report one case, discuss the outpatient management of patients who have ventriculoatrial shunts, and comment on previously reported Japanese adult cases.

\section{Case Report}

A 41-year-old man with a previous history of subarachnoid hemorrhage, visited our outpatient clinic for evaluation of moderate proteinuria in October 1990. He had had a V-A (ventriculoatrial) shunt implanted following secondary hydrocephalus 4 years previously. His physical examination showed no abnormal findings. The urinary protein was almost $1 \mathrm{~g} / \mathrm{gCr}$ (gram creatinine).
Serum creatinine was $0.9 \mathrm{mg} / \mathrm{dL}$, BUN (blood urea nitrogen) $18.9 \mathrm{mg} / \mathrm{dL}$, total protein $7.2 \mathrm{~g} / \mathrm{dL}$, albumin $4.1 \mathrm{~g} / \mathrm{dL}$, total cholesterol $129 \mathrm{mg} / \mathrm{dL}$, sodium $146 \mathrm{mEq} / \mathrm{L}$, potassium $4.4 \mathrm{mEq} / \mathrm{L}$, chloride $107 \mathrm{mEq} / \mathrm{L}$, CRP (C reactive protein) $1.0 \mathrm{mg} / \mathrm{dL}, \quad \operatorname{IgG} 1835 \mathrm{mg} / \mathrm{dL}, \quad \operatorname{IgA}$ $219 \mathrm{mg} / \mathrm{dL}, \mathrm{IgM} 195 \mathrm{mg} / \mathrm{dL}, \mathrm{CH}_{50} 8 \mathrm{u} / \mathrm{mL}, \mathrm{C}_{3} 45 \mathrm{mg} / \mathrm{dL}$, $\mathrm{C}_{4} 33.6 \mathrm{mg} / \mathrm{dL}$, fasting blood sugar was $83 \mathrm{mg} / \mathrm{dL}$ and antinuclear antibody \& anti-DNA antibody were negative. Tumor marker such as CEA and $\alpha$-feto protein were negative. At a follow-up clinic visit one year later, he complained of general malaise and was noted to have bilateral lower extremity edema. During the subsequent two months, urinary protein increased from $2.2 \mathrm{~g} / \mathrm{gCr}$ to $9.2 \mathrm{~g} / \mathrm{gCr}$. Examination of urinary sediment disclosed numerous red cells and white cells, oval fatty bodies, and some granular casts. CRP increased from $1.0 \mathrm{mg} / \mathrm{dL}$ to $5.1 \mathrm{mg} / \mathrm{dL}$. At the same time, albumin decreased from $2.9 \mathrm{~g} / \mathrm{dL}$ to $1.8 \mathrm{~g} / \mathrm{dL} . \mathrm{C}_{3}$ was $16 \mathrm{mg} / \mathrm{dL}, \mathrm{C}_{4} 12 \mathrm{mg} / \mathrm{dL}$, and CIC (circulating immune complex) was $110.1 \mathrm{ng} / \mathrm{mL}$ $\left(\mathrm{C}_{1 \mathrm{q}}\right.$ binding assay) (Fig. 1). Hematological data were as follows; WBC $6700 / \mathrm{mm}^{3}$, RBC $375 \times 10^{4} / \mathrm{mm}^{3}$, hemoglobin $11.5 \mathrm{~g} / \mathrm{dL}$, hematocrit $33.9 \%$, Plt $20.5 \times 10^{4} / \mathrm{mm}^{3}$. He was admitted to our hospital. Body height was $168 \mathrm{~cm}$; body weight $60 \mathrm{~kg}$; body temperature $36.4^{\circ} \mathrm{C}$; blood pressure $150 / 88 \mathrm{mmHg}$. One blood culture grew coagulase negative staphylococcus sensitive to ampicillin, but the other subsequent repeated blood cultures were

From the First Department of Internal Medicine, Faculty of Medicine, the University of Tokyo, Tokyo

Received for publication November 16, 1992; Accepted for publication March 10, 1993

Reprint requests should be addressed Dr. Eisei Noiri, the First Department of Internal Medicine, Faculty of Medicine, the University of Tokyo, 7-3-1, Bunkyo-ku, Tokyo 113, Japan 
sterile. Namely, one of two venous culture samplings was positive. A renal biopsy was performed immediately after admission. Histological examination showed the following:

Light microscopy: Glomerulus showed diffuse mesangial cell proliferation and lobulation of all the glomerular tufts. Furthermore, tram-tracking sign of the basement membrane was seen on PAM stain (Fig. 2).

Immunofluorescence: Immunofluorescence microscopy revealed depositions of $\operatorname{IgG}, \operatorname{IgA}, \operatorname{IgM}, \mathrm{C}_{3}, \mathrm{C}_{4}, \mathrm{C}_{1 \mathrm{q}}$ and fibrinogen along the glomerular capillary walls in a fringe pattern (Fig. 3).

Electronmicroscopy: Mesangial cells had proliferated to form a pattern of so-called mesangial interposition. Other characteristic findings were subendothelial electron dense deposits and fusion of foot processes (Fig. 4).

Based on the these histological findings, this case was diagnosed as mesangiocapillary glomerulonephritis (or membranoproliferative glomerulonephritis (MPGN), type I). A close relation between MPGN and his V-A shunt was suspected in the light of the above-mentioned infectious signs, such as increment of CRP value and coagulase negative staphylococcus positive in blood culture. From December 1991 to May 1992, he was followed as an outpatient. During this period, he was prescribed ampicillin against coagulase negative staphylococcus, the suspected pathogen. As a result, urinary protein and CRP decreased from $9.2 \mathrm{~g} / \mathrm{gCr}$ to $4.7 \mathrm{~g} / \mathrm{gCr}$, and from $5.1 \mathrm{mg} / \mathrm{dL}$ to $1.5 \mathrm{mg} / \mathrm{dL}$, respectively. Additionally, albumin, $\mathrm{C}_{3}$, and $\mathrm{C}_{4}$ increased from $1.8 \mathrm{~g} / \mathrm{dL}$ to $2.8 \mathrm{~g} / \mathrm{dL}$, from $16 \mathrm{mg} / \mathrm{dL}$ to $36 \mathrm{mg} / \mathrm{dL}$ and from $12 \mathrm{mg} / \mathrm{dL}$ to 19.2 $\mathrm{mg} / \mathrm{dL}$, respectively (Fig. 1). These trends were thought to be additional supportive evidence for a close relationship between MPGN and an infected V-A shunt.

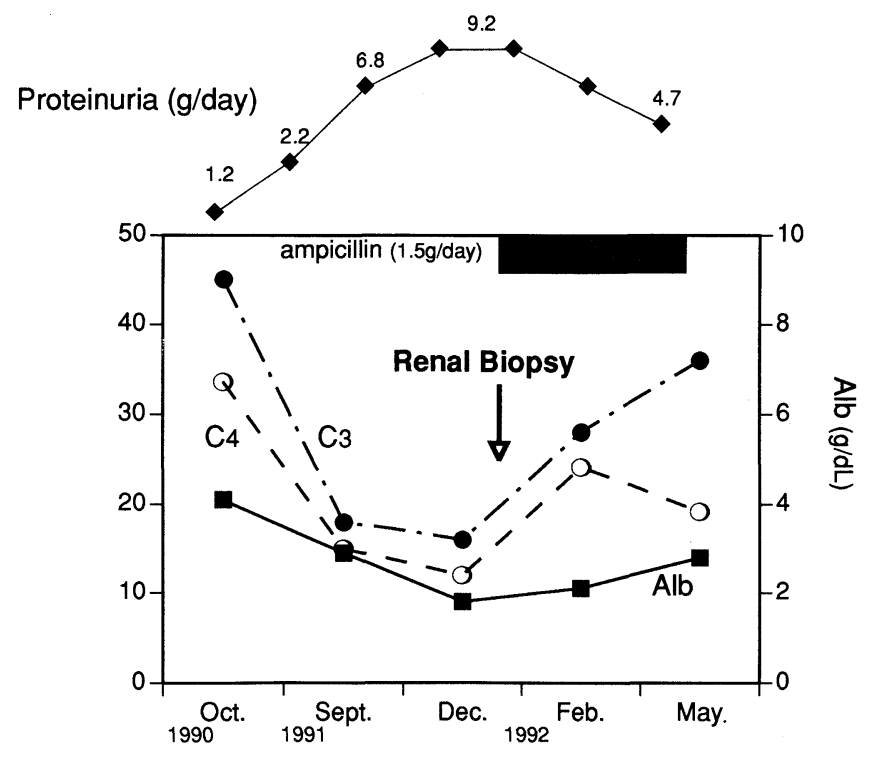

Fig. 1. Clinical Course

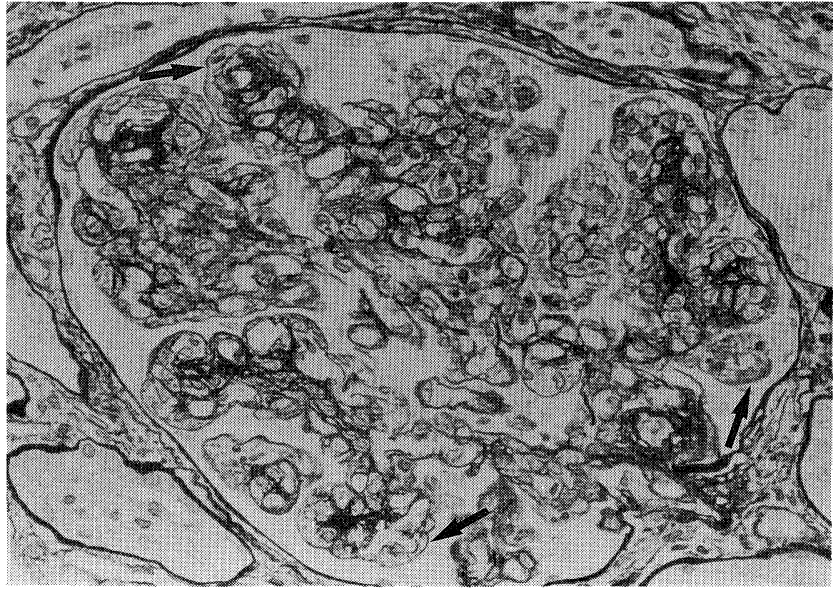

Fig. 2. Light microscopy PAM stain $(\times 200)$ Glomerulus showed diffuse mesangial cell proliferation and lobulation of all the glomerular tufts, with tram-tracking sign of the basement membrane (arrow).

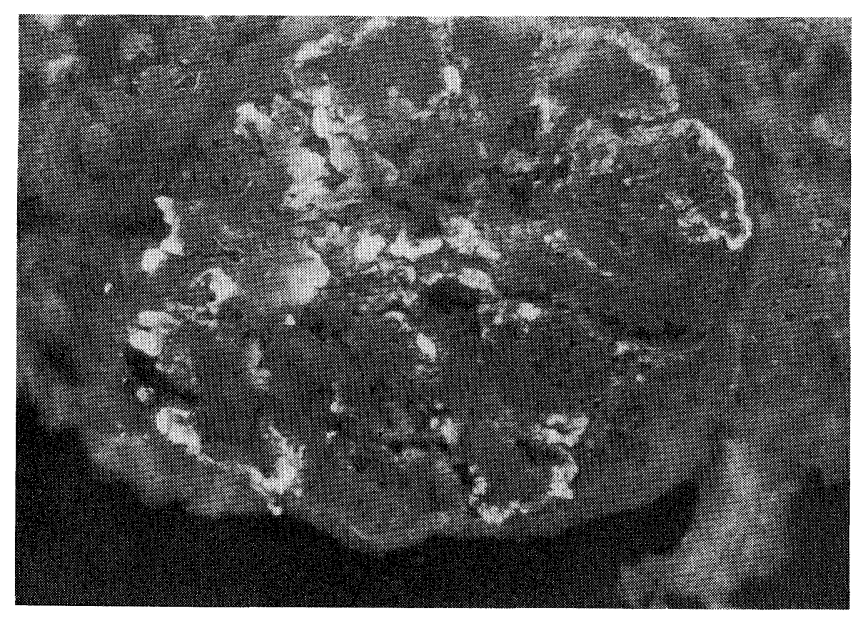

Fig. 3. Immunofluorescence of $\mathrm{C}_{1 \mathrm{q}}(\times 200)$ Intense staining along the glomerular capillary walls for $\mathrm{C}_{1 \mathrm{q}}$ with some areas of a fringe pattern.

Therefore, he was re-admitted to our hospital for removal of the V-A shunt on May 11, 1992. At removal, a thin slimy white film was seen at the tip of the shunt. Culture of the V-A shunt and the Spitz-Holter valve yielded a growth of coagulase negative staphylococci.

\section{Discussion}

A possible diagnosis of shunt infection should be entertained and ruled out when a patient with an indwelling shunt visits the outpatient clinic. It is understandably annoying to get back a report of a culture positive for coagulase negative staphylococci, as in most patients this only reflects probable contamination and even if truly positive, is a very weakly virulent pathogen in most 


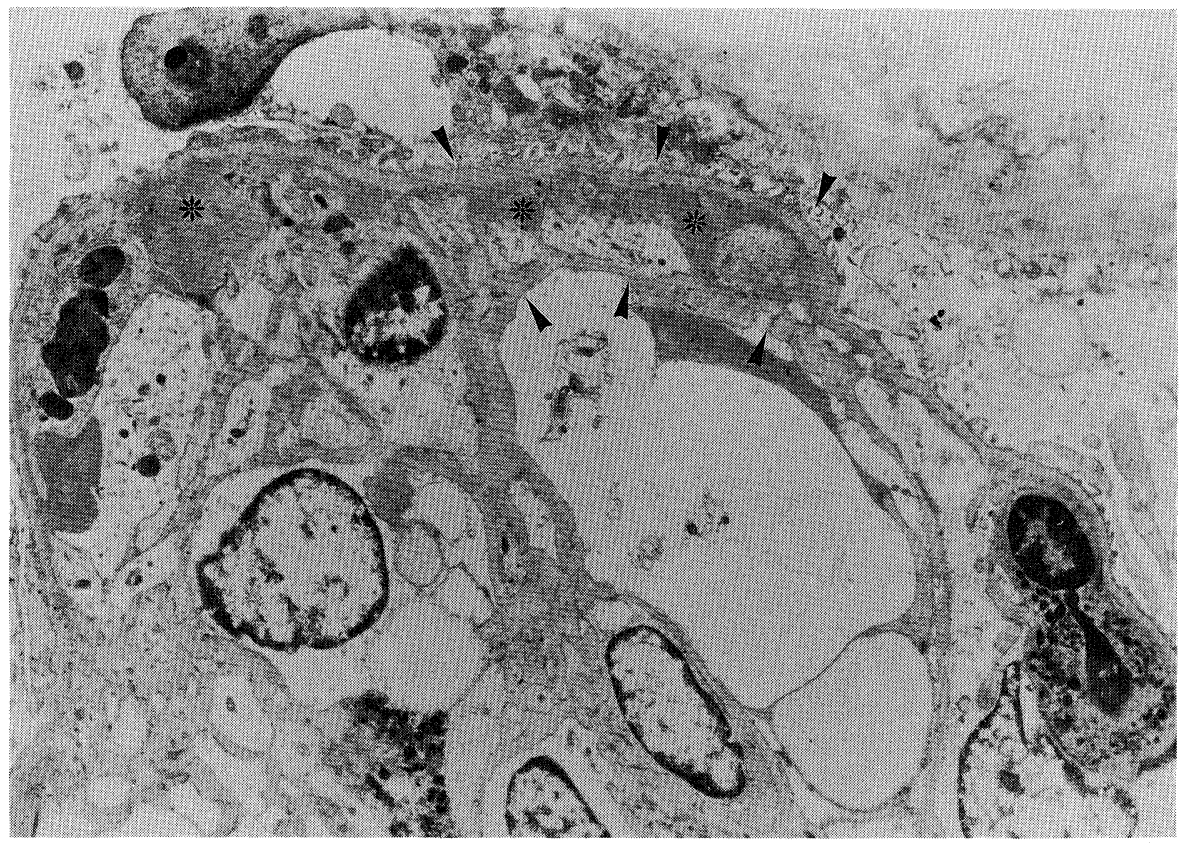

Fig. 4. Electron microscopy (Uranyl acetate and lead citrate; $\times 5000$ )

Glomerular capillary wall showing double basement membrane-like material due to mesangial interposition located between the endothelium and the basement membrane (arrow head). Discrete electron-dense osmiophilic deposits are present throughout the subendothelial space (asterisk).

patients. However, the clinician must bear in mind that coagulase negative staphylococcus is identified as the pathogen in nearly 70 to 80 percent of shunt infections. Therefore, a blood culture positive for this organism is considered diagnostic of infection in shunt patients. After confirming coagulase negative staphylococci both in blood culture and in shunt or valve culture, it is easy to postulate a close relationship between existing urinary abnormalities and shunt infection and to diagnose it as shunt nephritis (2). However, before removing the shunt, it is difficult to confirm the diagnosis properly as shunt nephritis, even if some characteristic blood data such as complement, CIC and cryoglobulins, are helpful $(3,4)$, because there is also the possibility that patients suffer from some glomerulonephritis such as membranous nephropathy, minimal change nephrotic syndrome, mesangial proliferative glomerulonephritis, membrano-proliferative glomerulonephritis, systemic lupus erythematosus or others, independent of their shunts.

In the present case, supporting evidence for shunt nephritis were hypocomplementemia, mildly high CRP value (5), and the presence of CIC, as is usual for shunt nephritis. As for the clinical diagnosis in this particular case, the fact that antibiotic therapy (ampicillin) not only regained his CRP value, but also his proteinuria, hypoalbuminemia, CIC value and hypocomplementemia proved to be meaningful. Based on this evaluation, it was confirmed that his glomerulonephritis was due to an infectious rather than a primary or collagenous etiology. Diminution of the infectious antigen-induced nephritiogenic mediator by ampicillin ameliorated the consumption of the complement activities, which improved the CIC value and proteinuria. The overall rate of $\mathrm{V}$-A shunt infection itself varies from 3 to $11 \%$ (6). Moreover, shunt nephritis has been found to occur in 0.7 to $2.25 \%$ of patients with an infected shunt (7). Taken together, it is a rare complication, and some nephritogenic strains of coagulase negative staphylococci will cause this disease entity. It is important to discuss the necessity of periodic urinalysis examination and routine serum albumin and complement profiles for patients with an indwelling shunt. Moreover, once shunt nephritis is suspected, it is worthwhile to try antibiotics for a therapeutic diagnosis.

In Table 1, the previously reported Japanese adult cases are summarized ( 7 cases including our case). All of these patients in whom V-A shunts were placed, suffered from secondary hydrocephalus due to subarachnoid hemorrhage or accidental trauma. The duration between the time of shunt insertion and the onset of nephritis varies from 0.5 to 13 years. Similar to that previously reported (8), light microscopical findings in these cases show membranoproliferative or mesangial proliferative glomerulonephritis with or without crescent formation. Electron microscopic findings reveal subendothelial electron-dense deposits in all cases $(9,4)$. Mesangial 
NoIRI et al

Table 1. Adult Japanese Reported Cases

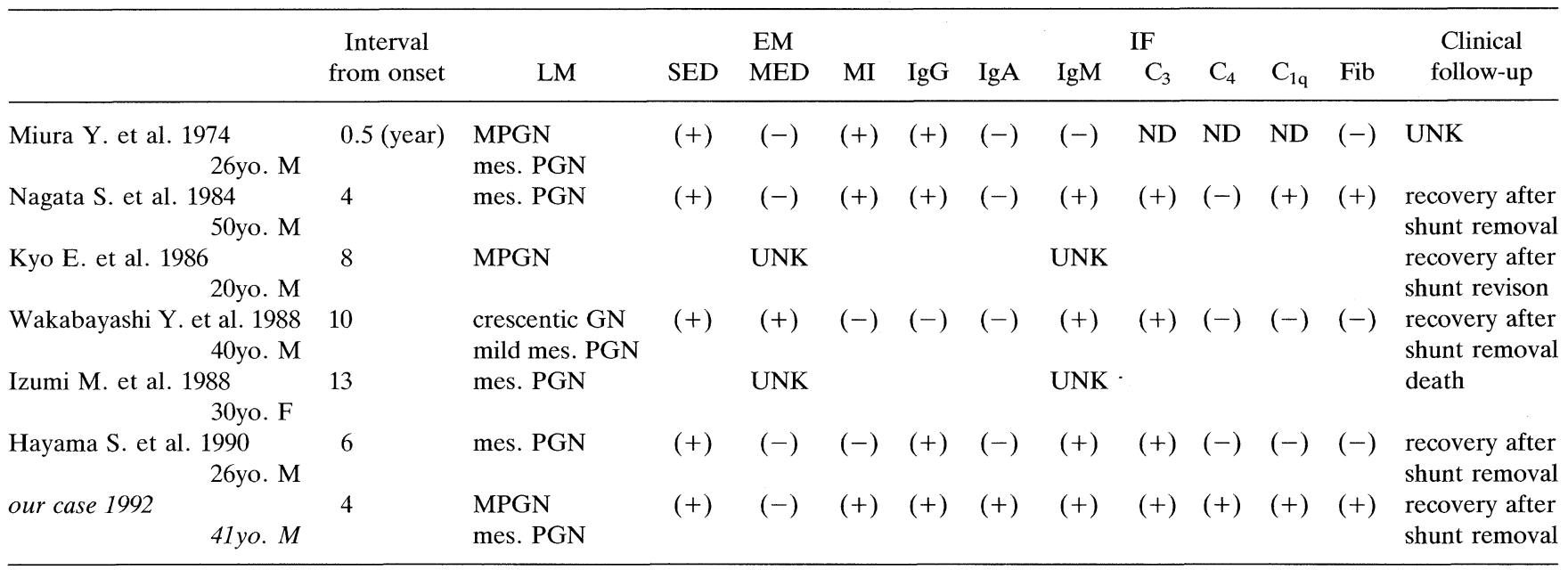

Coagulase (-) staphylococcus was identified as causative organism in all cases. SED: subendothelial deposits, MED: mesangial deposits, MI: mesangial interposition, GN: glomerulonephritis, MPGN: membranoproliferative glomerulonephritis, mes.PGN: mesangial proliferative glomerulonephritis, LM: light microscopy, EM: electron microscopy, IF: immunofluorescence, UNK: unknown, ND: not done.

interposition, which is one of the typical features of mémbrano-proliferative glomerulonephritis, is disclosed in three of five cases for which pathological findings were available. Immunofluorescent studies show positive staining for $\mathrm{C}_{3}$ in all cases; and for $\mathrm{IgG}$ and $\mathrm{IgM}$ in four of five cases. Positive staining for early components of complement $\left(\mathrm{C}_{4}\right.$ and $\left.\mathrm{C}_{1 \mathrm{q}}\right)$ suggests that the classical pathway may be important in our patient. Depending on the nature of the glomerular change, there is general consensus that after removal of the $\mathrm{V}$-A shunt, the prognosis of shunt nephritis is fair. A complete renal functional recovery is reported to be expected in about $50 \%$ of patients $(10)$. This trend is borne out in these reported patients. The only patient in Table 1 reported to have died was diagnosed as nephrotic syndrome and treated with pulsed methyl-prednisone therapy without removal of the shunt. Her renal function deteriorated and death occured soon after initiating hemodialysis therapy. Therefore, soon after confirming the diagnosis of an infected V-A shunt, the shunt should be removed or replaced.

Acknowledgements: We appreciate Norma Wyse, M.D. for her critical reading of this manuscript.

\section{References}

1) Black JA, Challacombe DN, Ockenden BG. Nephrotic syndrome associated with bacteremia after shunt operations for hydrocephalus. Lancet 4: 921, 1965.

2) Peters G, Locci R, Pulverer G. Adherence and growth of coagulase negative staphylococci on surface of intravenous catheters. J Infect Dis 146: 479, 1982.

3) Shena FP, Pertosa G, Pastore A, De Tommasi A, Montagna MT, Bonomo L. Circulating immune complexes in infected ventriculoatrial and ventriculoperitoneal shunts. J Clin Immun 3: 173, 1983.

4) Dobrin RS, Day NK, Quie PG, et al. The role of complement, immunoglobulin and bacterial antigen in coagulase-negative staphylococcal shunt nephritis. Am J Med 59: 660, 1975.

5) Arze RS, Rashid H, Morley R, Ward MK, Kerr DNS. Shunt nephritis: Report of two cases and review of the literature. Clin Nephrol 19: 48, 1983.

6) Forrest DM, Cooper DGW. Complication of ventriculoatrial shunts. A review of 455 cases. J Neurosurg 29: 506, 1968.

7) Narchi H, Taylor R, Azmy AF, et al. Shunt nephritis. J Pediatr Surg 23: 839, 1988.

8) Wakabayashi Y, Kobayashi Y, Shigematsu H. Shunt nephritis: Histological dynamics following removal of the shunt. Nephron 40: 111, 1985.

9) Coleman M, Burnett J, Barratt LJ, Dupont P. Glomerulonephritis associated with chronic bacterial infection of a dacron arterial prosthesis. Clin Nephrol 20: 315, 1983.

10) Rifkinson-Mann S, Rifkinson N, Leong $T$. Shunt nephritis. J Neurosurg 74: 656, 1991. 